\title{
Analisis Keamanan Jaringan Pada Web Dari Serangan Sniffing Dengan Metode Eksperimen
}

\author{
Yacob Hae* ${ }^{1}$, Wiwin Sulistyo \\ ${ }^{1,2} \mathrm{Jl}$. Diponegoro 52-60, Salatiga 50711, Indonesia \\ ${ }^{3}$ Jurusan Teknik Informatika, FTI UKSW, Salatiga \\ e-mail : ${ }^{1} 672017030 @$ student.uksw.edu, ${ }^{2}$ wiwin.sulistyo@uksw.edu
}

\begin{abstract}
Abstrak
Keamanan jaringan pada masa ini memang sangat dibutuhkan, karena pada saat ini banyak sekali data - data dari pengguna internet telah dicuri dan dimanfaatkan untuk hal - hal yang tidak baik, maka dari itu salah satu solusi untuk mencegah pencurian data terjadi maka keamanan pada sebuah web pun ditinggkatkan untuk mencegah terjadinya pencurian data oleh para hacker. HTTPS adalah protokol web yang sampai saat ini diterapkan pada semua web dan juga sudah menjadi standar untuk sebuah web yang mana HTTPS merupakan bagian teraman dari HTTP, dengan menggunakan HTTPS pada web maka data seperti email dan password pun akan menjadi lebih aman, namun tentu saja meskipun web sudah memakai HTTPS tetap saja selalu ada celah yang dapat dimanfaatkan oleh hacker untuk mencuri informasi dari targetnya. Pada penelitian ini akan menunjukkan bahwa meskipun web telah memakai protokol HTTPS yang merupakan bagian teraman dari HTTP hacker tetap bisa mencuri data dengan cara menurunkan protokol web yang harusnya HTTPS menjadi HTTP dengan teknik sniffing yang dibantu dengan tools Bettercap. Hasil akhir pada penelitian ini adalah dimana hacker berhasil menurunkan protokol web yang awalnya HTTPS menjadi HTTP dan akhirnya mendapatkan infomasi berupa plain text yang tidak lagi terenkripsi seperti NIM dan password dari user.
\end{abstract}

Kata kunci-Bettercap, Sniffing, Man In The Middle, Kali Linux

\begin{abstract}
Network security at this time is really needed, because at this time a lot of data from internet users has been stolen and used for things that are not good, therefore one solution to prevent data theft from happening is security on a web. enhanced to prevent data theft by hackers. HTTPS is a web protocol that until now is applied to all webs and has also become the standard for a web where HTTPS is the safest part of HTTP, by using HTTPS on the web data such as email and passwords will become more secure, but of course even if the web already uses HTTPS, but there are always loopholes that hackers can exploit to steal information from their targets. This study will show that even though the web has used the HTTPS protocol which is the safest part of HTTP, hackers can still steal data by lowering the web protocol that should be HTTPS to HTTP with sniffing techniques assisted by Bettercap tools. The final result of this research is where the hacker succeeded in lowering the web protocol which was originally HTTPS to HTTP and finally got information in the form of plain text that is no longer encrypted such as NIM and password from the user.
\end{abstract}

Keywords-Bettercap, Sniffing, Man In The Middle, Kali Linux 


\section{PENDAHULUAN}

Pada saat ini kemajuan dan perkembangan teknologi telah berkembang sangat pesat. Keamanan pada sebuah jaringan menjadi sangat penting dan harus selalu diperhatikan, jaringan yang talah terhubung pada internet tentu sangat tidak aman karena rentan terjadinya pencurian data oleh para hacker, baik itu pada jaringan LAN atau pun pada jaringan wireless. Pada saat data dikirim melewati beberapa terminal untuk sampai tujuan, yang berarti hal ini akan memberikan kesempatan pada user lain yang tidak bertanggung jawab untuk menyadap atau mengubah data, bahkan sampai mencuri data tersebut untuk kepentingan pribadi. Dalam pembangunan perancangan, sistem keamanan jaringan yang terhubung ke internet harus dipersiapkan dengan matang dan dimengerti dengan baik agar dapat menjaga data - data penting yang berada pada jaringan tersebut secara efektif dan meminimalisir terjadinya serangan oleh para hacker ataupun cracker. Beberapa tempat yang dapat cukup rawan yang bisa terkena sniffing, contohnya seperti di tempat belajar seperti universitas, tempat santai seperti coffee shop dimana hacker atau cracker dapat mencuri data email dan password dari para user lain yang berada dalam satu jaringan dengan para hacker.[1]

Keamanan pada sebuah web menjadi salah satu hal yang harus diperhatikan karena dengan adanya kemanan pada sebuah web artinya informasi dari user yang menggunkan web tersebut bisa menjadi lebih aman. Namun perlu juga untuk selalu diperhatikan bahwa keamanan pada web harus selalu di update karena jika tidak cepat atau lambat keamanan tersebut dapat ditemukan celahnya oleh para hacker yang ingin mencuri informasi pada web tersebut, sebagai salah satu contoh yang dapat diterapkan pada keamanan web yaitu menggunakan protokol kemanan seperti HTTPS yang dapat mengamankan web dari serangan hacker, tapi dengan hanya menggunakan HTTPS belum cukup untuk mengamankan web, sebagai contoh pada penelitian ini penulis akan mencoba menurunkan protokol kemanan web yang harusnya menggunakan HTTPS menjadi HTTP, pada penelitian ini web yang akan menjadi bahan sebagai penelitian adalah "siasat.uksw.edu" yang dimana webiste ini adalah website yang sering digunakan mahasiswa Universitas Kristen Satya Wacana untuk melakukan registrasi mata kuliah.

\subsection{Tinjauan Pustaka}

\section{METODE PENELITIAN}

Menurut penelitian yang berjudul"Analisis Sniffing Password Menggunakan Aplikasi Cain dan Abel Pada Jaringan Wifi Universitas Semarang", penelitian ini membahas tentang pengujian jaringan wifi dengan menggunakan tools Cain dan Abel yang dimana tools ini bisa digunakan untuk menangkap/melihat username dan password yang masuk dalam jaringan[1].

Pada penelitian "analisis keamanan jaringan pada fasilitas internet (wifi) terhadap serangan packet sniffing" membahas tentang bagaimana cara mengamankan jaringan wifi dari packet Sniffing. Tools yang digunakan penulis pada penelitiannya adalah Ettercap[2].

Dan penelitian yang berjudul "Analisis Penyadapan Pada Jaringan Website Dengan Protokol HTTP Menggunakan Metode Sniffing dengan Tools Bettercap (Studi Kasus Website Berbol)" meneliti tentang bagaimana tools Bettercap bekerja pada website yang tidak memiliki protokol keamanan pada websitenya seperti HTTPS yang artinya web tersebut hanya menggunkan HTTP sebagai protokol webnya yang berarti setiap user yang memasukkan informasi mereka ke dalam website tersebut akan mudah diambil oleh hacker[3].

Pada penelitian yang berjudul "Pemanfaatan Bettercap Sebagai Teknik Sniffing Pada Paket Trafik Jaringan WIFI" membahas tentang pengujian paket trafik pada user yang 
menggunakan internet melalui koneksi jaringan wifi public dengan menggunkan serangan Man In The Middle Attack[4].

Pada penelitian yang berjudul "Sniffing Pada Jaringan WiFi Berbasis Protokol 802.1x Menggunakan Aplikasi Wireshark" membahas tentang proses sniffing dengan menggunakan wireshark dan berhasil mendapatkan kode otentikasi station pada jaringan WiFi berbasis 802.1X[5].

Pada penelitian yang berjudul "Analisa Kinerja Jaringan pada Internet Connection Sharing menggunakan Virtual Access Point dan Real Access Point" penulis membandingkan tentang kinerja jaringan untuk internet connection sharing menggunakan virtual access point dengan real access point yang lebih stabil[6].

Pada penelitian yang berjudul "Analisa Dan Simulasi Keamanan Jaringan Ubuntu Server Dengan Port Knocking, Honeypot, Iptables, Icmp" membahas bagaimana mengamankan port pada server dari serangan hacker yang menggunakan honeypot dengan menggunakan metode port knoking[7].

Dalam penelitian "Analisis Kemanan Jaringan Internet (Wifi) dari Serangan Packet Data Sniffing Di Universitas Muhammadiyah Palembang" membahas tentang keamanan wifi pada salah satu universitas di Palembang, dimana salah satu web pada universitas tersebut berhasil terkena packet sniffing sehingga username dan password dari user yang menggunakan web tersebut berhasil terlihat[8].

Pada penelitian yang berjudul" Efektivitas Sniffer Menggunakan Natural Language dalam Pembelajaran"membahas tentang bagaimana scapy dalam pembuatan aplikasi pembelajaran lalu lintas protokol dengan menggunakan bahasa pemrograman python[9].

Dan pada penelitian yang berjudul "Analisis Serangan Man in the Middle (MitM) Menggunakan Firmware Hacking Glinet Router 6416a di Jaringan Wireless Artikel Ilmiah" membahas bagaimana teknik Man in the Middle menggunakan firmware hacking pada router Glinet 6416a di jaringan wireless dimana hasil akhir dan penelitian ini penulis berhasil mendapatkan username dan password dari user yang terlah menjadi target[10].

\section{2 Landasan Teori}

\section{2.1 Bettercap}

Bettercap adalah software yang masuk dalam kategori open source dan tools keamanan jaringan untuk serangan Man-In-The-Middle, aplikasi tersebut hanya berjalan pada jaringan LAN dengan kerja menganalisis suatu jaringan protocol komputer dan mengumpulkan informasi paket yang dikirim dan diterima oleh komputer lain. Teknik Bettercap adalah melakukan Intersep pada jaringan dan mengubah trafik pada sebuah segmen jaringan, menangkap password pada IP Host target.

\section{2.2 Virtual Box}

Virtual Box adalah salah satu software yang dapat digunakan untuk menjalankan beberapa sistem operasi dalam sistem operasi utama, contohnya dapat menjalan Linux dan Windows sekaligus dalam waktu yang bersamaan. Dengan menggunakan Virtual Box hacker dapat menjalankan Kali Linux tanpa harus menghapus sistem operasi utama.

\section{2.3 Kali Linux}

Kali linux adalah sistem operasi yang berbasis debian dikembangkan oleh Offensive Security. Kali Linux lebih sering digunakan untuk melakukan penetrasi sistem, keamanan pada web dan juga pada jaringan. Dalam penelitian ini Kali Linux dibutuhkan untuk menjalankan tools Bettercap dan menjadi sistem operasi utama dari hacker. 


\section{2.4 Wireless Adapter}

Wireless Adapter adalah sebuah perangkat yang digunakan untuk menambah konektivitas jaringan nirkabel/wireless pada laptop atau komputer. Dengan adanya wireless adapter juga sangat membantu hacker dalam melakukan penetrasi pada jaringan internet tapi perlu dipastikan bahwa wireless adapter yang digunakan dapat melakukan monitor mode dan packet injection.

\section{2.5 Sistem Operasi Windows}

Sistem operasi Windows adalah sistem operasi yang paling umum digunakan oleh banyak orang dikarenakan Windows memiliki tampilan interface yang cukup mudah dipahami oleh semua kalangan dan juga sudah banyak aplikasi yang support menggunakan sistem operasi Windows. Pada penelitian ini fungsi dari sistem operasi Windows adalah menjadi target dari hacker.

\subsection{Metodologi Penelitian dan Perancangan}

Pada penetilitan ini penulis menggunakan metode eksperimen yang dimana metode ini digunakan untuk melakukan eksperimen pada salah satu web milik Universitas Kristen Satya Wacana yaitu "siasat.uksw.edu" yang dimana pada penelitian ini penulis mencoba tingkat keamanan pada protokol web tersebut dengan cara melakukan sniffing.

\subsection{Tahapan Penelitian}

Dalam perencanaan analisis jaringan keamanan pada web maka diperlukan beberapa tahap agar penelitian dapat berjalan dengan baik seperti pada Gambar 1 berikut.

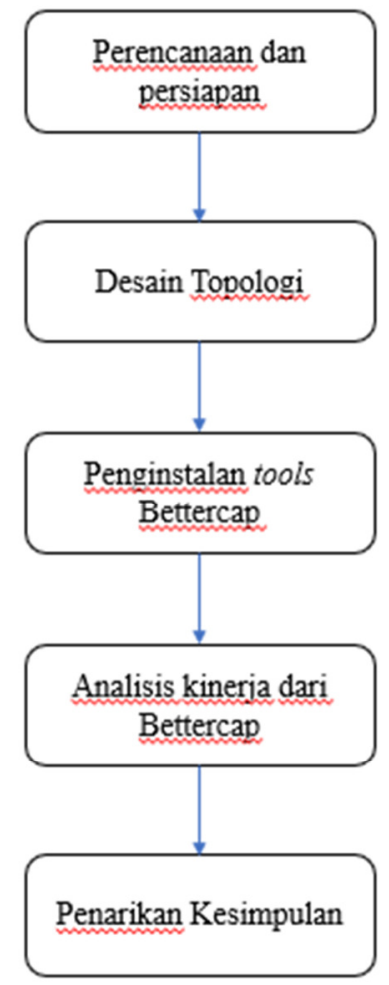

Gambar 1. Metode Penelitian 
Pada Gambar 1. Merupakan tahapan - tahapan yang dilakukan selama penelitian. Pada tahap pertama adalah perencanaan yang dimana pada tahap ini penulis merencanakan apa yang yang harus disiapkan untuk melakukan penelitian lalu dilanjutkan dengan membuat topologi yang akan dipakai dalam penelitian ini, berikut pada gambar 2 adalah topologi yang digunakan pada penelitian ini :

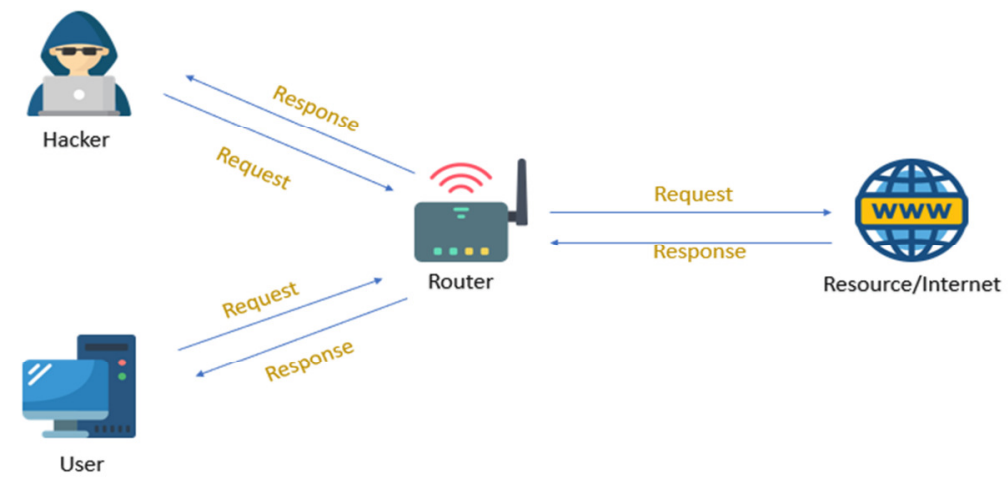

Gambar 2. Topologi normal

Pada gambar 2 merupakan topologi yang biasaya digunakan semua orang yang dimana setiap user akan langsung berhubungan dengan router, akan tetapi ketika jaringan telah disadap maka topologi akan berubah seperti pada gambar 3 berikut ini :

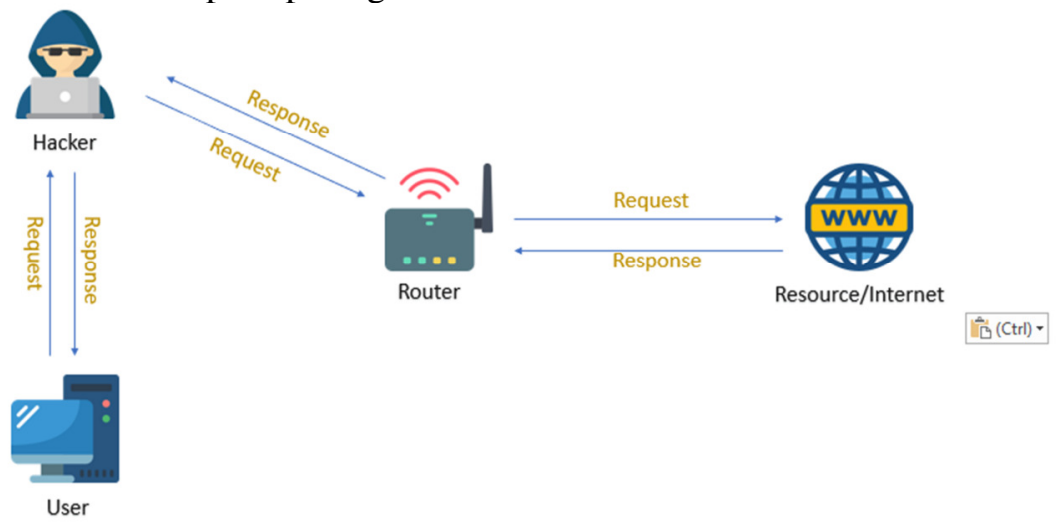

Gambar 3. Hacker menerapkan serangan Man In The Middle Attack

Seperti gambar diatas inilah yang terjadi ketika koneksi jaringan internet telah diretas oleh hacker dan dengan teknik Man In The Middle Attack hacker berhasil menempatkan dirinya ditengah - tengah user dan router yang artinya setiap kali user melakukan request maka akan terlihat juga oleh hacker apa yang di request oleh user dan begitu pun pada router yang bertugas menerima request dari user dan melakukan response terhadap permintaan user yang dimana response tersebut juga akan dilihat oleh hacker yang telah berada di tengah - tengah user dan router, dengan begitu hacker dapat melihat aktivitas user saat menggunakan internet dan juga dapat mencuri data user.

Pada tahap berikutnya penulis akan melakukan penginstalan tools yang akan digunakan yaitu Bettercap, berikut adalah command yang digunakan untuk mengintal Bettercap :

Table 1. installasi Bettercap.

sudo apt-get update

sudo apt-get install bettercap 


\section{Jatisi}

ISSN 2407-4322

Vol. 8, No. 4, Desember 2021, Hal. 2095-2105 E- ISSN 2503-2933

Setelah tools Bettercap terinstal maka selanjutnya adalah menjalankan tools tersebut dan melakukan penyerangan pada protokol web siasat.uksw.edu melewati user yang telah menjadi target, setelah berhasil melakukan penyerangan pada protokol web maka akan dilanjutkan dengan menganalisa hasil dari Bettercap apakah mendapatkan informasi dari web tersebut atau tidak. Pada tahap akhir dari penelitian ini adalah menarik kesimpulan dari hasil yang telah didapatkan oleh Bettercap.

\section{HASIL DAN PEMBAHASAN}

Setelah melakukan Sniffing dengan menggunakan tools Bettercap maka penulis mendapatkan beberapa informasi dari hasil penelitian pada website "siasat.uksw.edu" yang dimana website tersebut berhasil di downgrade dari HTTPS ke HTTP yang artinya semua informasi yang dienkripsi oleh protocol HTTPS tidak lagi terenkripsi yang artinya informasi tersebut dapat dengan mudah dianalisis dan dibaca oleh penulis.

Dalam penelitian ini terdapat beberapa langkah - langkah yang digunakan untuk mengubah HTTPS ke HTTP :

\section{Menjanlankan tools}

Pada tahap pertama adalah menjalankan tools Bettercap yang sudah terinstall pada Kali Linux.

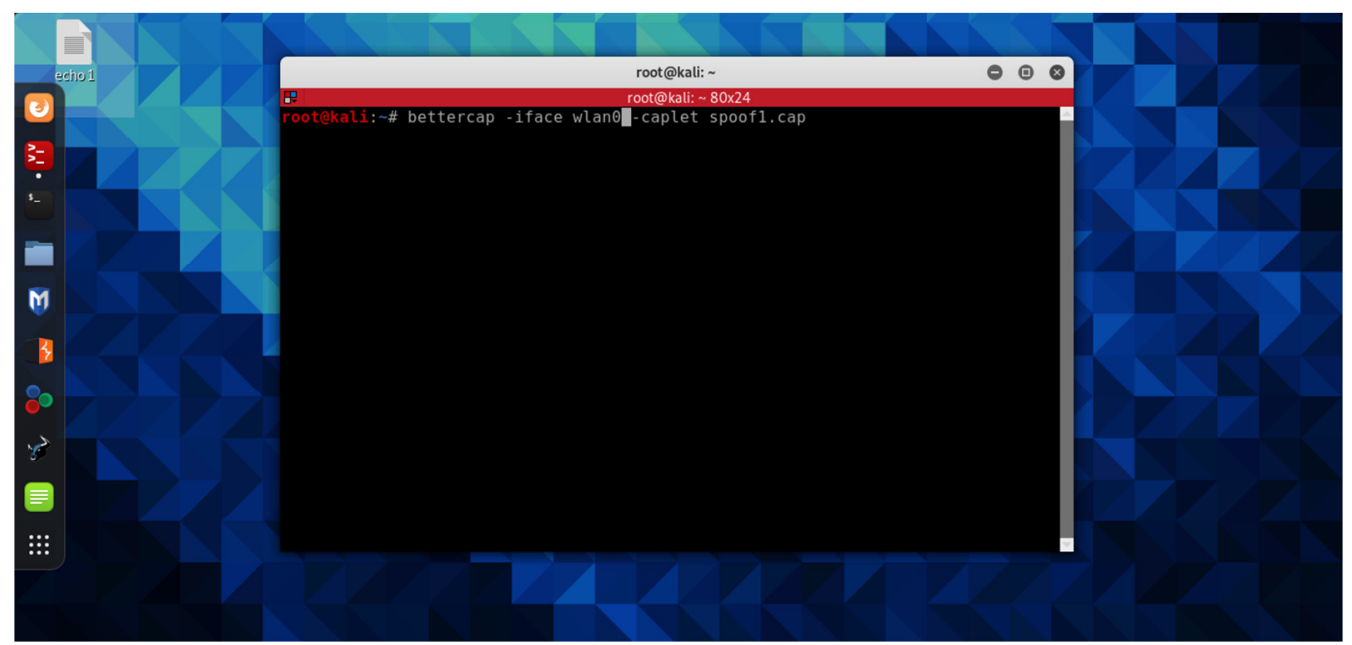

Gambar 4. Menjalankan Bettercap

Pada gambar 4 adalah command yang digunakan untuk menjalankan Bettercap dan sekaligus menjalankan script yang telah dibuat untuk menyerang user yang telah menjadi target dan untuk commandnya sendiri dimulai dari "bettercap" yang digunakan untuk menjalankan tools tersebut dan ikuti oleh "-iface" yang digunakan untuk menentukan interface yang akan digunakan dan untuk melihat interface apa saja yang ada pada Kali Linux dapat menggunakan command "ifconfig" lalu ada "wlan0" yang merupakan interface yang terpasang pada Kali Linux yang dimana interface ini berasal dari wireless adapter yang terhubung pada laptop, setelah itu ada "-caplet" yang merupakan perintah untuk membaca file script yang telah dibuat dan yang terkahir adalah "spoof1.cap" yang adalah file script yang dipakai pada penelitian ini.

Hae, et., al [Analisis Keamanan Jaringan Pada Web Dari Serangan Sniffing Dengan Metode Eksperimen] 


\section{Bettercap telah berjalan}

Berikut pada gambar 5 adalah tampilan saat Bettercap telah berjalan dengan command yang telah dimasukkan pada gambar 4.

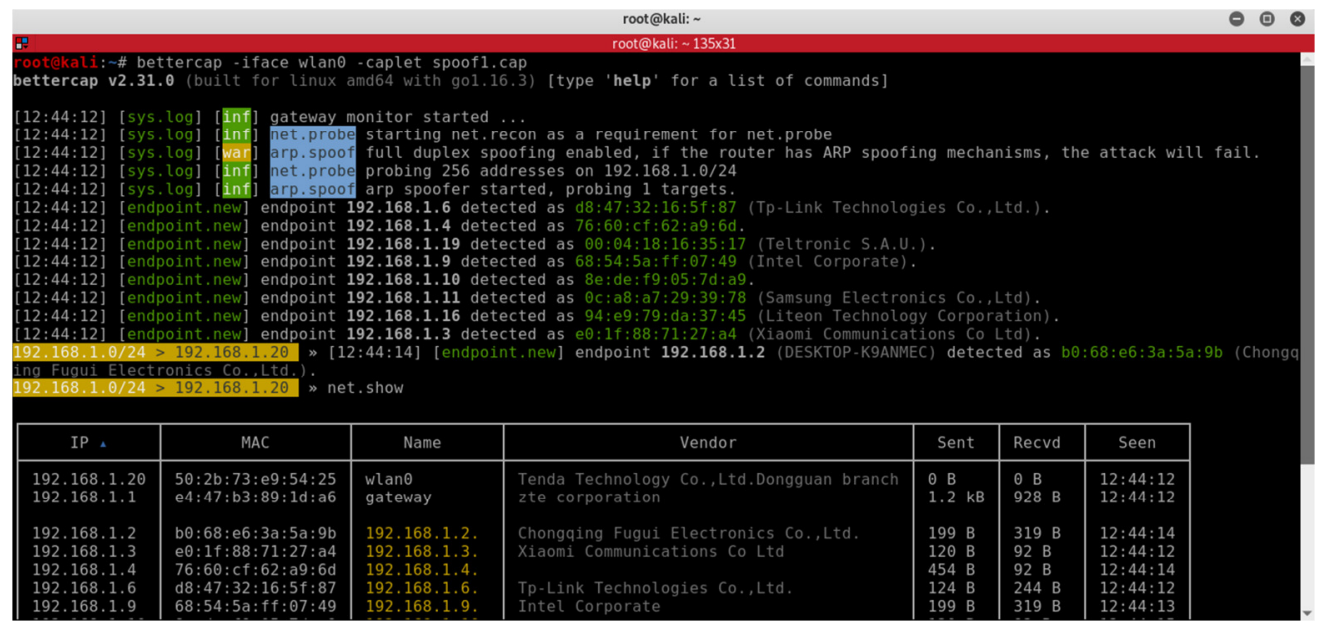

Gambar 5. Bettercap telah berjalan

Setalah tools Bettercap sudah berjalan maka sekarang tools Bettercap sudah bisa digunakan untuk menyerang user yang sudah dijakdikan target yang dimana target tersebut menggunakan sistem operasi Windows. Pada tampilan pada gambar diatas juga terdapat beberapa ip, dan ip dari Kali Linux adalah pada baris pertama yaitu "192.168.1.20" dengan Mac Addressnya "50:2b:73:e9:54:25" dan pada ip ini juga yang digunakan untuk menjadi interface yang digunakan pada gambar 4 yaitu Wlano.

\section{Tampilan pada Windows}

Pada tahap ini akan menunjukkan sisi dari user yang memakai sistem operasi Windows yang dimana telah menjadi target oleh hacker.

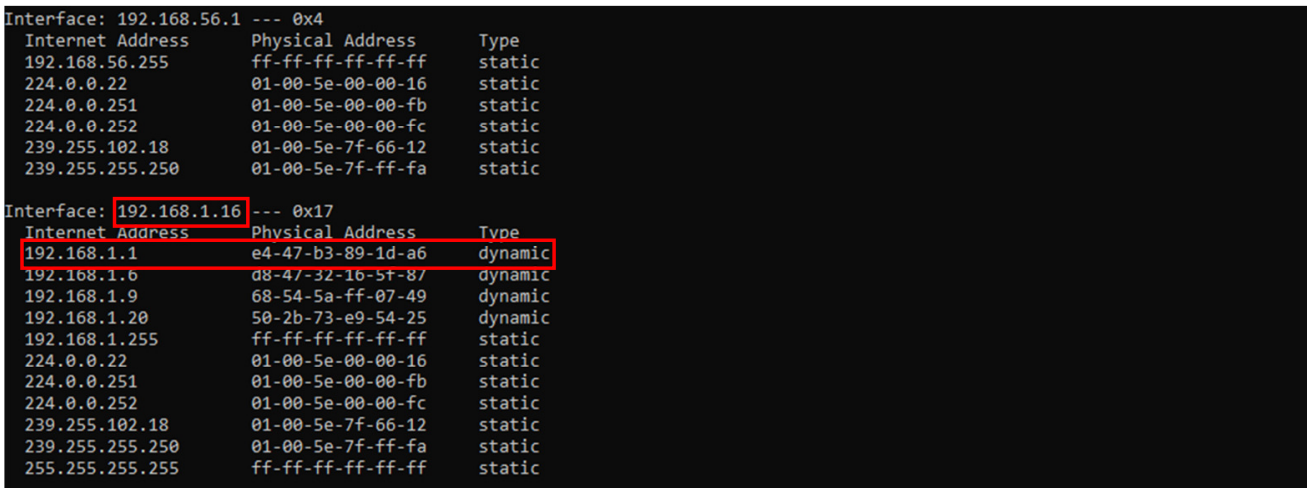

Gambar 6. IP pada windows dan IP pada router

Pada gambar 6 menunjukkan ip address dari user yang telah menjadi target dan juga ip address dari router yang akan diserang, pada gambar diatas juga menunjukkan bahwa physical address pada router masih terlihat baik - baik saja karena perintah pada gambar 4 belum dijalankan, namun setelah command dari gambar 4 telah dijalankan maka yang akan terjadi adalah seperti pada gambar berikut. 


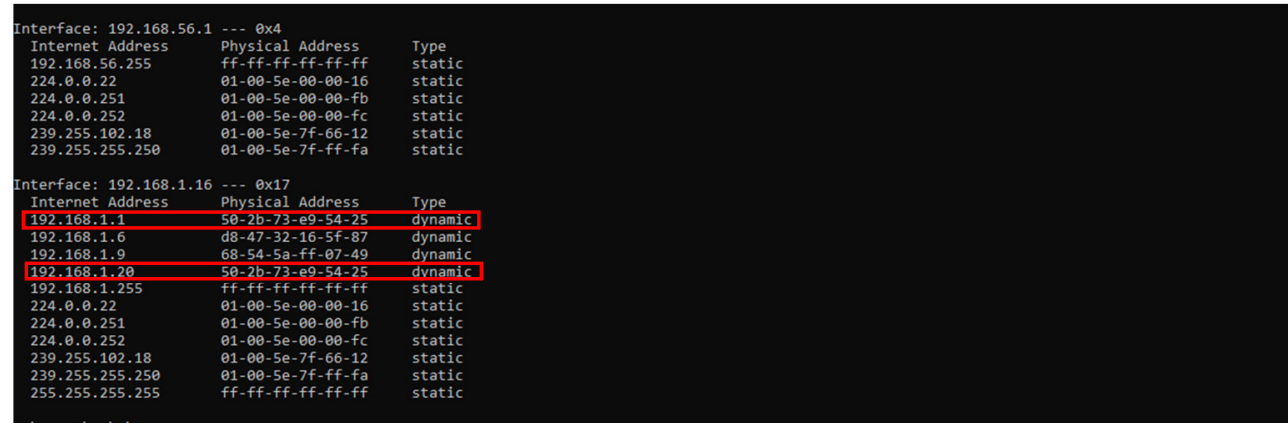

Gambar 7. Physical Address router terkena serangan

Bisa dilihat pada gambar 7. bahwa sniffing telah berjalan dan pada ip 192.168.1.1 yang merupakan ip dari router utama telah berhasil di serang dan terlihat juga pada physical address yang telah berubah dan menjadi sama dengan physical address milik ip 192.168.1.20 yang merupakan ip dari Kali Linux, yang artinya saat Windows melakukan aktivitas menggunakan internet maka semua informasi yang di request oleh Windows akan masuk terlebih dahulu pada Kali Linux lalu diteruskan pada router begitu pun sebaliknya saat router merespon permintaan Windows, informasi yang diberikan router akan terlebih dahulu dikirim pada Kali Linux lalu dikirim pada Windows, dengan kata lain Kali Linux akan menangkap dan membaca semua informasi yang telah request oleh Windows.

\section{Membuka Browser}

Pada tahap ini user akan membuka browser dan mencoba membuka sebuah web seperti "siasat.uksw.edu" yang dimana protokol keamanan dari web tersebut sudah menggunakan HTTPS namun karena sudah terkena serangan sniffing maka protokol kemanan web tersebut akan berubah menjadi HTTP yang artinya saat sudah menjadi HTTP data yang harusnya sudah terenkripsi akan secara otomatis akan berubah menjadi plain text dan akan dengan mudah untuk mencuri data dari user yang telah menjadi target.

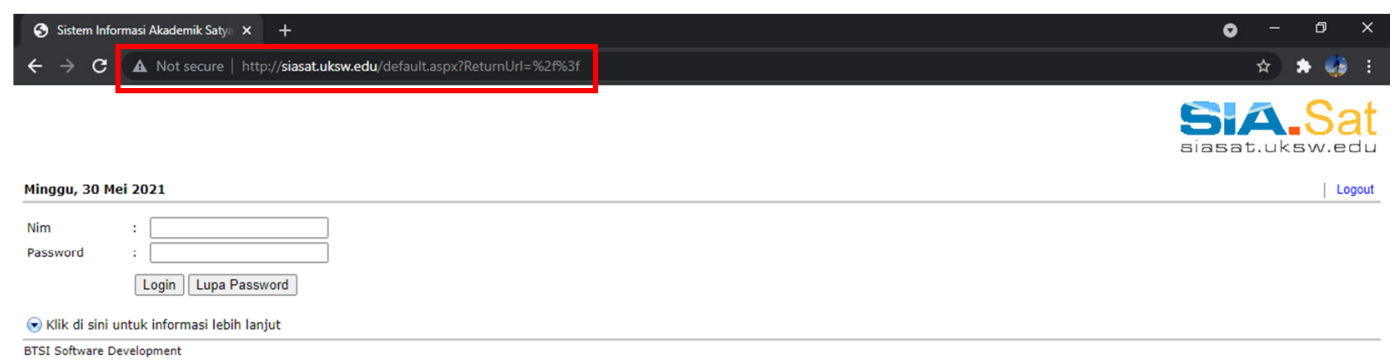

Gambar 8. Protokol web berubah menjadi HTTP dari HTTPS

Seperti yang terlihat pada gambar 8, ini merupakan tampilan dari web "siasat.uksw.edu", dan juga dapat dilihat pada bagian protokol web yang telah berhasil diturunkan menjadi HTTP. 


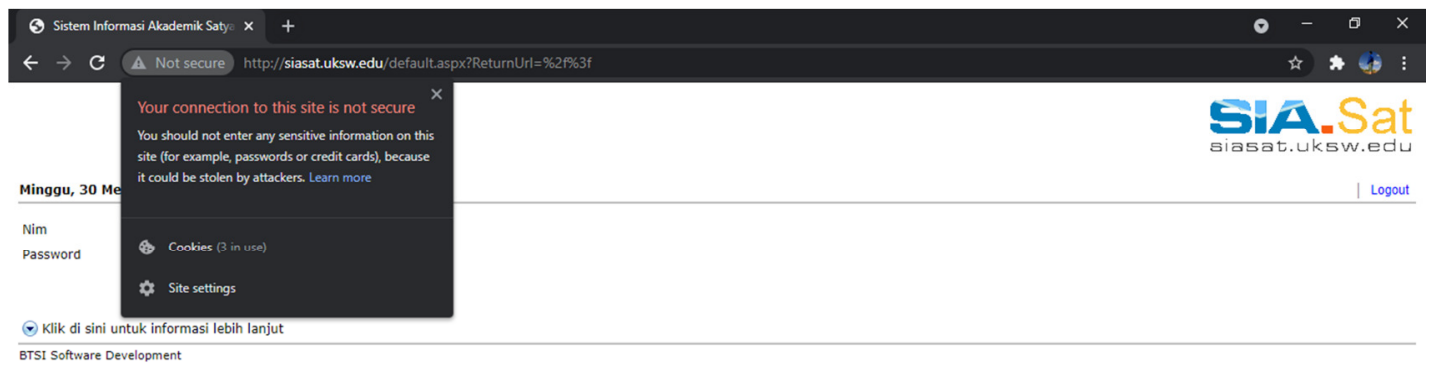

Gambar 9. Koneksi pada web siasat tidak aman

Pada gambar 9. Adalah gambar yang menjelaskan bahwa koneksi internet tidak aman dikarenakan protocol yang digunakan web tersebut adalah HTTP dan bukan HTTPS sehingga membuat data menjadi tidak aman dan mudah dicuri oleh hacker.

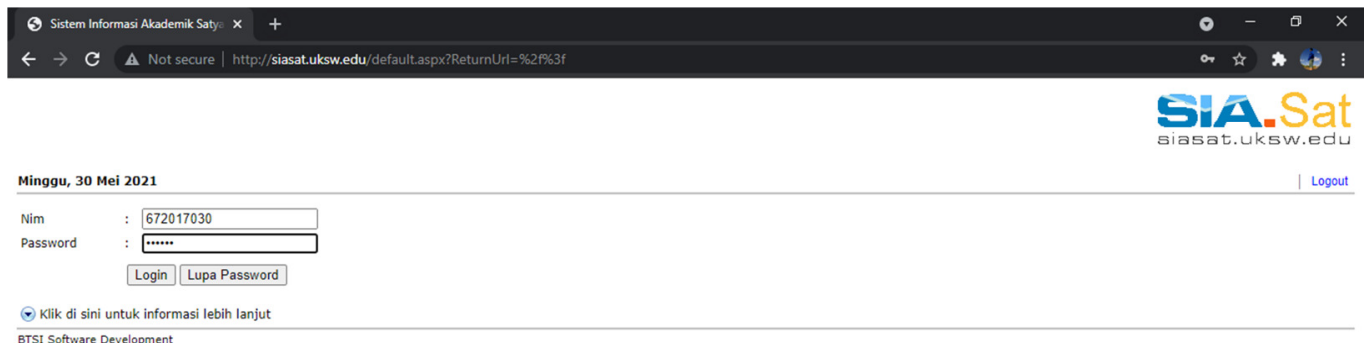

Gambar 10. User memasukkan NIM dan Password

Pada gambar 13. target memasukkan NIM dan password pada situs web "siasat" yang protokolnya telah diretas menjadi HTTP, yang berarti NIM dan password dari target akan dengan mudah di dapatkan oleh hacker.

\section{Hasil Capture}

Pada tahap ini aka menunjukan apa yang terjadi jika user tidak berhati - hati saat memasukkan NIM dan password pada web "siasat.uksw.edu" yang protokol webnya telah diturunkan menjadi HTTP.

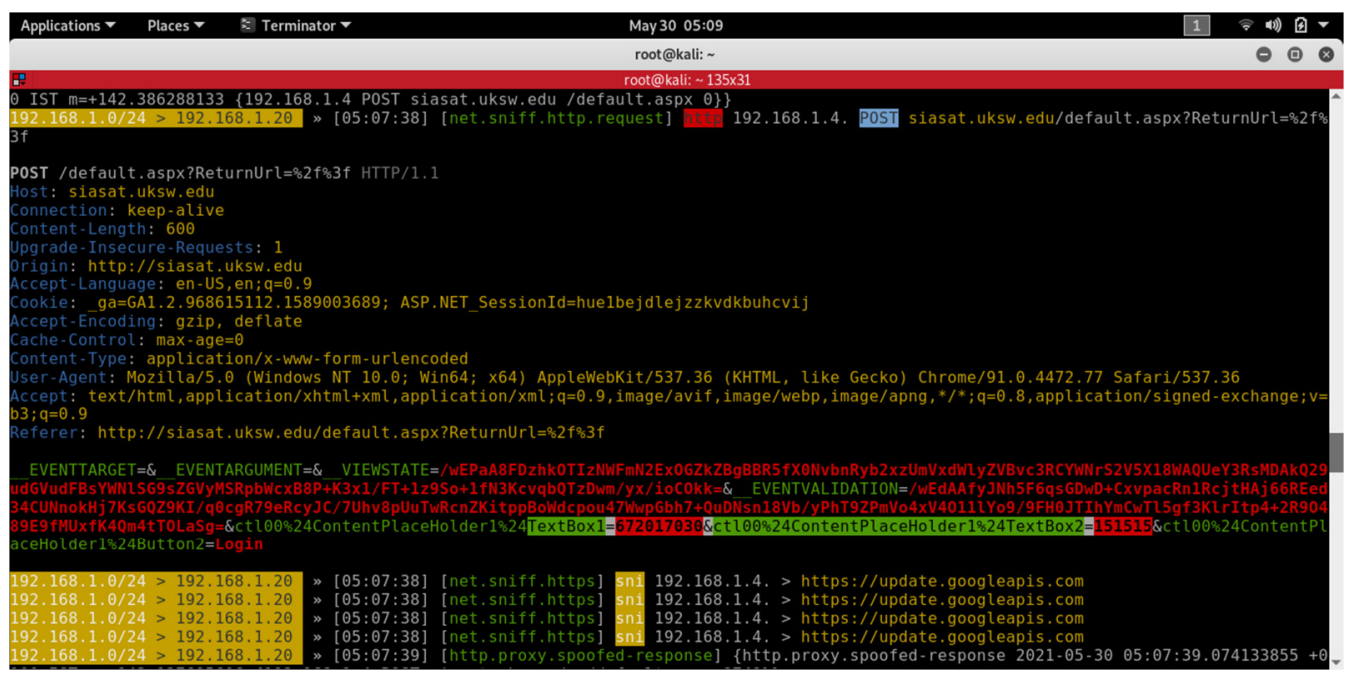

Gambar 11. Hasil Capture pada Kali Linux 
Pada gambar 14. inilah yang terjadi ketika target memasukkan NIM dan password pada web siasat yang protokol webnya telah diretas dan menjadi HTTP, bisa dilihat pada "TextBox1=672017030 dan pada TextBox2=151515" yang merupakan NIM dan password dari korban yang telah menjadi target oleh hacker. Dengan demikian hacker telah mempunyai informasi dari target tujuannya yang artinya sekarang hacker dapat mengakses siasat dari targetnya.

\section{KESIMPULAN}

Berdasarkan penelitian yang telah dilakukan diatas maka dapat disimpulkan bahwa Bettercap adalah tools yang cukup baik dalam melakukan peretasan pada sebuah web, dimana protokol dari web yang semulanya harusnya HTTPS berhasil diturunkan menjadi HTTP, namun ada sedikit kelemahan pada tools ini contohnya seperti terjadinya error saat menjalankan tools tersebut yang dimana salah satu dari error yang terjadi adalah tidak dapat mendeteksi ip router yang mengakibatkan penelitian tidak dapat berjakan dengan baik.

\section{SARAN}

Saran yang terbaik yang disampaikan penulis adalah kiranya penelitian menggunakan tools Bettercap tidak hanya sampai disini, namun dapat dilanjutkan lagi dimana masih banyak sekali module dari tools ini yang masih belum dipakai dalam penelitian ini, sekiranya pada penelitian selanjutnya dapat dikembangkan lagi dengan menggunakan module - module lain yang telah disediakan oleh Bettercap.

\section{UCAPAN TERIMA KASIH}

Ucapan terima kasih kepada Tuhan Yang Maha Esa yang telah melancarkan penelitian ini dari awal sampai pada akhir penelitian, dan juga kepada dosen pembimbing yang telah membimbing penulis selama masa penelitian dan kepada keluarga yang telah mendukung dalam doa dan yang terakhir pada teman - teman yang juga telah membantu menyemangati sampai pada akhir penelitian ini

\section{DAFTAR PUSTAKA}

[1] S. Susanto, B. A. Pramono, and S. Handayani, 2018, "Analisis Sniffing Password Menggunakan Aplikasi Cain dan Abel pada Jaringan Wifi Universitas Semarang," J. Transform., Vol. 16, No. 1, p. 67, doi: 10.26623/transformatika.v16i1.787.

[2] B. A. Nugroho, 2012. "Analisis Keamanan Jaringan Internet,"

[3] K. Riset, D. A. N. P. Tinggi, U. Maritim, R. Ali, F. Keguruan, and D. A. N. Ilmu, 2018. "Surat Keterangan," No. November, p. 4500099,

[4] D. Kurnia, 2019. "Pemanfaatan Bettercap Sebagai Teknik Sniffing Pada Paket Trafik Jaringan Wifi,” Semin. Nas. Tek. UISU, Vol. 2, No. 1, pp. 83-85,

Hae, et., al [Analisis Keamanan Jaringan Pada Web Dari Serangan Sniffing Dengan Metode Eksperimen] 
[5] M. A. Abdillah, A. Yudhana, and A. Fadil, 2020, "Sniffing pada Jaringan WiFi Berbasis Protokol 802.1x Menggunakan Aplikasi Wireshark,” J-SAKTI (Jurnal Sains Komput. dan Inform., Vol. 4, No. 1, p. 1, doi: 10.30645/j-sakti.v4i1.181.

[6] S. A. Endarsa, 2013, "Analisa Kinerja Jaringan pada Internet Connection Sharing menggunakan Virtual Access Point dan Real Access Point,” p. 108,.

[7] H. B. S. M. K. Muhammad Iqbal, Arini MT, 2020, "Analisa dan Simulasi Keamanan Jaringan Ubuntu Server Dengan Port Knocking, Honeypot, Iptables, Icmp," CyberSecurity dan Forensik Digit., Vol. 3, No. 1, pp. 27-32,.

[8] E. M. Putra, B. Tujni, and E. S. Negara, "Analisis Kemanan Jaringan Internet (Wifi) dari Serangan Packet Data Sniffing di Universitas Muhammadiyah Palembang,” pp. 1-11.

[9] R. Sistem, 2021. "Efektivitas Sniffer Menggunakan Natural Language Dalam Pembelajaran," Vol. 1, No. 10, pp. 392-403,

[10] D. Wiharjo and I. R. Widiasari, 2019. "Analisis Serangan Man in The Middle (MitM) Menggunakan Firmware Hacking Glinet Router 6416 a di Jaringan Wireless Artikel Ilmiah,” No. 672018705, 